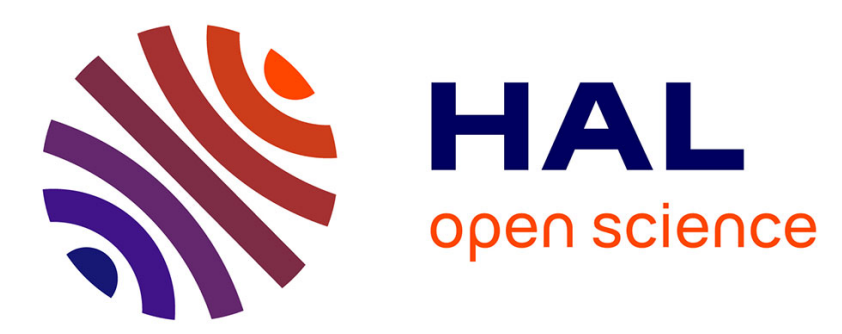

\title{
Evaluating stray current from DC electrified transit systems with lumped parameter and multi-layer soil models
}

Fabio Fichera, Andrea Mariscotti, Ade Ogunsola

\section{To cite this version:}

Fabio Fichera, Andrea Mariscotti, Ade Ogunsola. Evaluating stray current from DC electrified transit systems with lumped parameter and multi-layer soil models. IEEE EUROCON 2013, Jul 2013, Zagreb, Croatia. pp.1187-1192, 10.1109/EUROCON.2013.6625131 . hal-03266577

\section{HAL Id: hal-03266577 \\ https://hal.science/hal-03266577}

Submitted on 21 Jun 2021

HAL is a multi-disciplinary open access archive for the deposit and dissemination of scientific research documents, whether they are published or not. The documents may come from teaching and research institutions in France or abroad, or from public or private research centers.
L'archive ouverte pluridisciplinaire HAL, est destinée au dépôt et à la diffusion de documents scientifiques de niveau recherche, publiés ou non, émanant des établissements d'enseignement et de recherche français ou étrangers, des laboratoires publics ou privés. 


\title{
Evaluating Stray Current from DC Electrified Transit Systems with Lumped Parameter and Multi-Layer Soil Models
}

\author{
${ }^{1}$ Fabio Fichera, ${ }^{1}$ Andrea Mariscotti, IEEE Member, ${ }^{2}$ Ade Ogunsola, IEEE Senior Member \\ ${ }^{1}$ DITEN, University of Genova \\ Via Opera Pia 11A, 16145 Genova, Italy \\ ${ }^{2}$ Parsons International, \\ MENA, Abu Dhabi, UAE \\ andrea.mariscotti@unige.it \\ ade.ogunsoladparsons.com
}

\begin{abstract}
DC electrified traction systems are a potential source of stray current, that may corrode both internal and external structures and installations. The stray current intensity depends on several factors (traction current, rail insulation, concrete mat and piers resistance), that are accounted for in the proposed model. Moreover, the effect of a uniform or multi-layer soil model is considered, showing the differences and the impact on the countermeasures with respect to a uniform soil model simplifying approach.
\end{abstract}

Keywords: Corrosion, Electromagnetic conductive interference, Guideway transportation power systems, Power distribution electromagnetic interference, Stray current

\section{INTRODUCTION}

In DC electrified railway, the running rails are used for traction current return and form part of the signaling circuit for the control of train movements. However it is necessary to consider the consequences that this solution involves: as the running rails are isolated from ground, current will leak to ground, depending on the rail-to-earth conductance term for each running rail, with the ground now forming an unintended current return path.

In practice, limitation of the current leaking to ground and thus causing corrosion is implemented by decreasing the rail resistance and increasing the rail to earth resistance - achieved by adequate insulation and coating. A lower running rail resistance has the advantage of increasing the proportion of current propagating through the rails, while a greater rail to earth resistance has the advantage of limiting the amount of leakage current.

The earthing scheme implemented on a dc electrified railway largely influences the current distribution and thus the stray current [3]-[5]. When a metallic structure is electrically influenced by stray current, the potential of the structure shifts in the positive or in the negative direction where the current leaves or enters the metal surface. The positive potential deviation of the structure is a measurable effect which is used as electrolytic corrosion hazard criterion in standards and regulations of many countries. However such measurements are usually post construction and thus may lead to an expensive retrofit program, in the case of undesirable results.

Determining the response of the structure is not an easy task, because it is a function of three things: the location of the structure with respect to the electric flow field generated by the stray current source (protection system), the magnitude of the electric field, and the electrochemical response of the structure to the interference (protection).

In the electric circuit approach, based on the earth-return circuit theory, which is more suitable for modeling extended structures (pipelines, cables, etc.), the polarization phenomenon is not taken into account. Perhaps the first publication that provides a detailed analytical approach for the assessment of stray current is [6]. The formulation demonstrates the importance of keeping the leakage factor, the square root of the value of the rail resistance per unit length divided by the track-to-earth leakage resistance per unit length, as low as possible, and provides an analytical solution for the estimation of stray current for grounded and ungrounded dc electrified railways. It however does not consider the presence of a stray current collector mat and thus is only applicable to primary current leakages from rail to ground and not to modern metro and rapid transit systems.

Due to the limitation expressed above, analytical models have been developed by various researchers [3][5][7]-[9] for the estimation of stray current from dc-electrified railways. Explicit in these models is the assumption that the $\mathrm{dc}$ electrified railway is directly laid above ground; furthermore the analytical solutions gives no indication on the potential impressed on a buried metallic object nor an estimate of the corrosion current on a buried pipeline.

In [7] a distributed parameter model is presented, where the resistance of the various interposed structural elements (supporting element and stray current concrete mat, for example), as well as the grounding resistance of the viaduct piers, may be included in the mesh of resistive elements, that is part of the model.

\section{OVERVIEW OF THE MODEL STRUCTURE}

The considered model is a generic model describing a dcelectrified railway on a viaduct consisting of two Traction Power Stations (sourcing the currents $I_{1}$ and $I_{2}$, respectively) and one train, at a generic position $\mathrm{x}$ between 0 and $L$ and absorbing a constant current $I[10]$. 


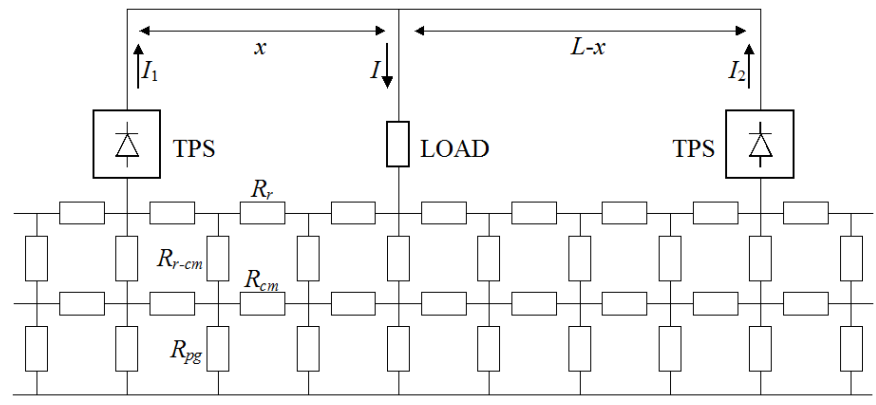

Fig. 1. Track scheme including the stray current mat and the viaduct piers [10]

The distributed parameter model in [10] for the same system represents the reference for the validation of the lumped parameter model developed successively. A lumped parameter model, following a circuit approach, seems a less elegant and a less performing solution to the same problem. Yet, the reason for investigating it resides in the possibility of introducing easily discontinuities and modeling different and complicated situations, for example introducing local defects in the rail fasteners, the sleepers, the ballast, the soil, buried metal structures and the grounding system. The overall accuracy is not sacrificed: stray current phenomena are low frequency, or dc in the present case, phenomena and do not require a fine grain representation in the longitudinal axis, thus keeping the spatial step size at a convenient value. For the results shown in the following $10 \mathrm{~m}$ were used, after a validation of the chosen value by means of a sensitivity analysis.

The lumped parameter model proceeds writing down the Kirchhoff equations and the constitutive equations for the series and shunt circuit elements; then the "sparse tableau method" is applied, obtaining a circuit representation as follows:

$$
\begin{aligned}
& {[A] I=0} \\
& V-[A]^{T} V_{n}=0 \\
& {[Y] V+[Z] I=U}
\end{aligned}
$$

where $I$ and $V$ represent the branch current and voltage vectors for all the elements of the circuit model, $V_{n}$ is the vector of the node voltages, $U$ is the vector of the external variables (either currents or voltages), $[Y]$ and $[Z]$ are admittance and impedance matrices and $[A]$ is an incidence matrix implementing the basic Kirchhoff equations.

This method leads to a square matrix that can be inverted, of size $2 R+N-1$, where $R$ is the number of branches and $N$ is the number of the nodes of the circuit:

$$
[T]=\left[\begin{array}{ccc}
1 & 0 & -[A]^{T} \\
{[Y]} & {[Z]} & 0 \\
0 & {[A]} & 0
\end{array}\right]
$$

The solution of the circuit model is automatic by inversion of $\mathrm{T}$. The model has a graphical user interface to ease the data input for simple cases and to display the main results, as shown in Fig. 2.

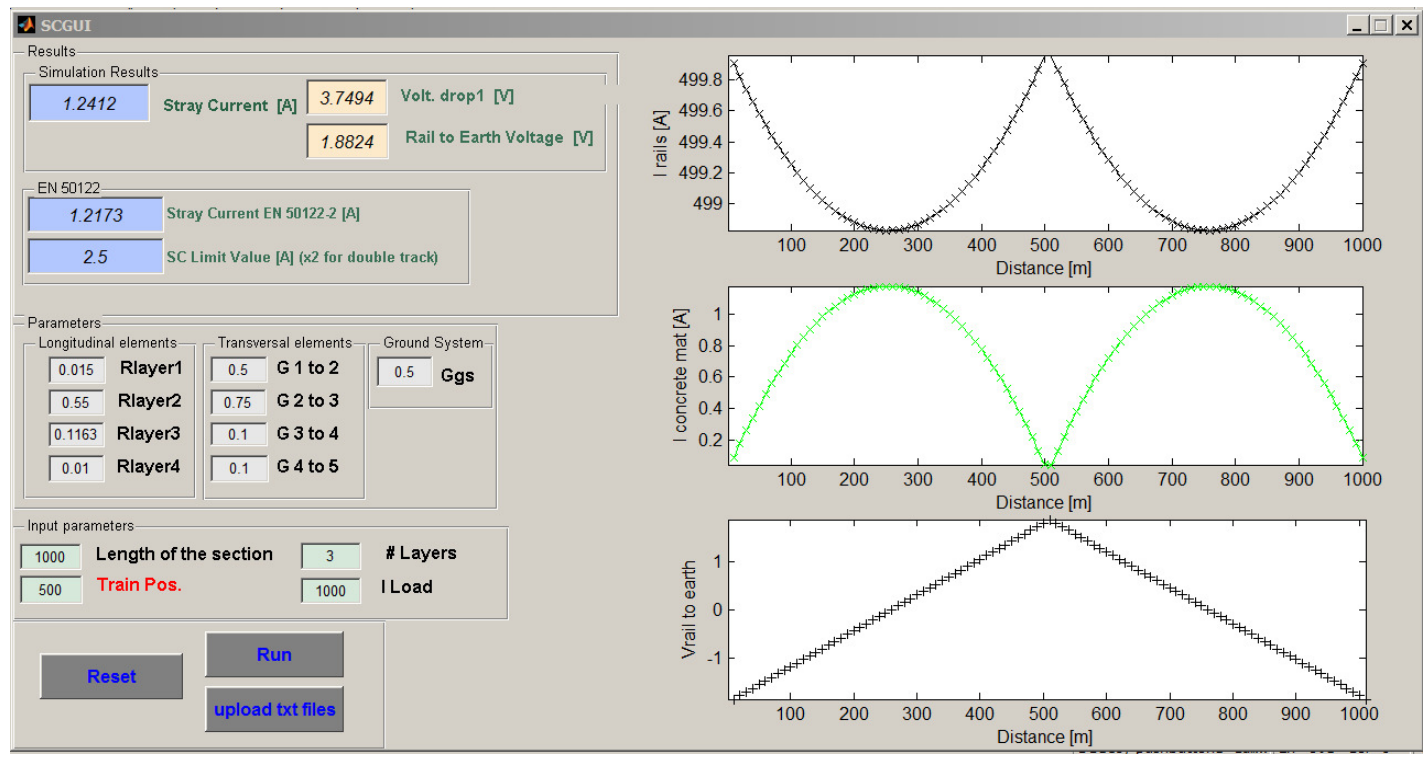

Fig. 2. Graphical user interface of the stray current calculator

\section{MODEL VERIFICATION AND SIMULATION RESULTS}

The verification has proceeded through initial simple cases, featuring only one layer of circuit elements, simulating the case of rails directly laid on a uniform ground (that includes the effects of the track ballast and soil), with no buried structures. Then, a stray current mat and later a buried pipe are added. Last, the uniform soil model is changed to a multilayer soil model. 


\section{A. Simple case of track on uniform soil, no buried structures}

This configuration was considered to perform a sensitivity analysis and a direct comparison with the expressions and values found in [1][2], where a similar configuration is assumed. Assuming the rails fastened to sleepers, sunk in the ballast and soil, with the rails electrically insulated from the sleepers themselves by an insulating pad, the following conductance terms can be identified: $G_{\text {rp }}$ for the rail to pad term, $G_{p s}$ for the pad to sleeper term, $G_{s b}$ for the sleeper to ballast term, and $G_{b e}$ for the ballast to earth term. For each term a minimum and maximum value, based on sensible assumptions and practical knowledge, has been assumed as shown in Table I.

TABLE I

TRACK CONDUCTANCE TERMS: MIN AND MAX VALUES

\begin{tabular}{l|c|c}
\hline \hline Param. & Min. value [S/km] & Max. value [S/km] \\
\hline \hline $\mathrm{G}_{\mathrm{rp}}$ & 0.002 & 200 \\
\hline $\mathrm{G}_{\mathrm{ps}}$ & 0.01 & 10 \\
\hline $\mathrm{G}_{\mathrm{sb}}$ & 0.02 & 0.8 \\
\hline $\mathrm{G}_{\mathrm{be}}$ & 0.01 & 100 \\
\hline \hline
\end{tabular}

The resulting min and max values for the overall rail to earth conductance $\mathrm{G}_{\mathrm{re}}$ (given by the series combination of the four terms above) are about 0.001 and $1.0 \mathrm{~S} / \mathrm{km}$. It can be noted that in the best track conditions (low conductance values for the four terms) $G_{r e}$ is strongly influenced by $G_{r p}$, whilst in the worst case of high conductance to earth $G_{r e}$ is limited by the ballast conductance value $\mathrm{G}_{\mathrm{be}}$.

With reference also to Fig. 1, the other parameter that is needed for this simplified configuration is the rail longitudinal resistance $R_{r}$ that is normally in the range of $0.03-0.08 \Omega / \mathrm{km}$, the track resistance $R_{t}$ for the two rails in parallel being half of it.

For a 1000 A absorbed train current and a TPS separation $L=3 \mathrm{~km}$, it is possible to calculate and plot the stray current per unit length as a functions of $G_{r e}$ and $R_{r}$ (see Fig. 3).

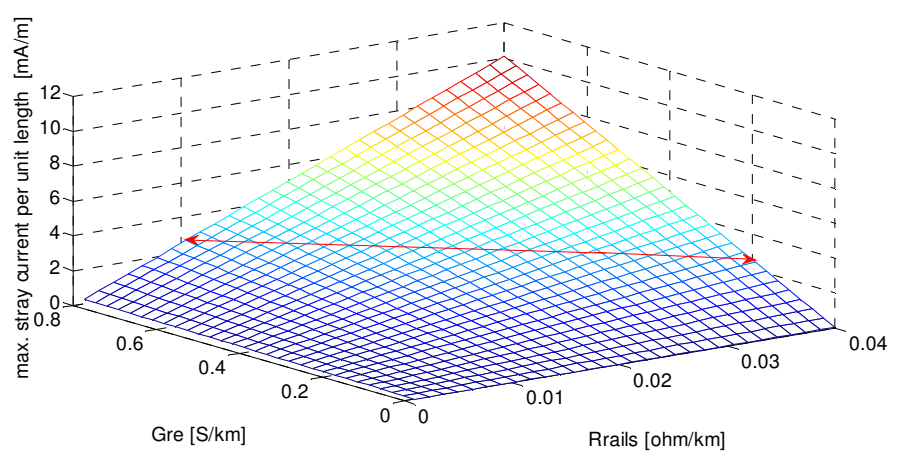

Fig. 3. Stray current per unit length as a functions of $G_{r e}$ and $R_{r}$

The calculated value is below the limit of $2.5 \mathrm{~mA} / \mathrm{m} \mathrm{[2]} \mathrm{if} \mathrm{it}$ lies in the portion below the horizontal arrow, that is for the maximum $G_{r e}$ value if $R_{t}$ is below $0.01 \Omega / k m$ and for the maximum $R_{t}$ value if $G_{r e}$ is below $0.19 \mathrm{~S} / \mathrm{km}$.
It is interesting to observe that the rail to earth voltage $U_{\text {re }}$ can be higher than the limit of $5 \mathrm{~V}$ prescribed in [1] for a $\mathrm{G}_{\mathrm{re}}$ $>0.5 \mathrm{~S} / \mathrm{km}$, without exceeding the limit on the stray current. This means that the two formulations for rail voltage and stray current given in [1][2] are not consistent for all parameter values, but bear an unexpressed safety margin.

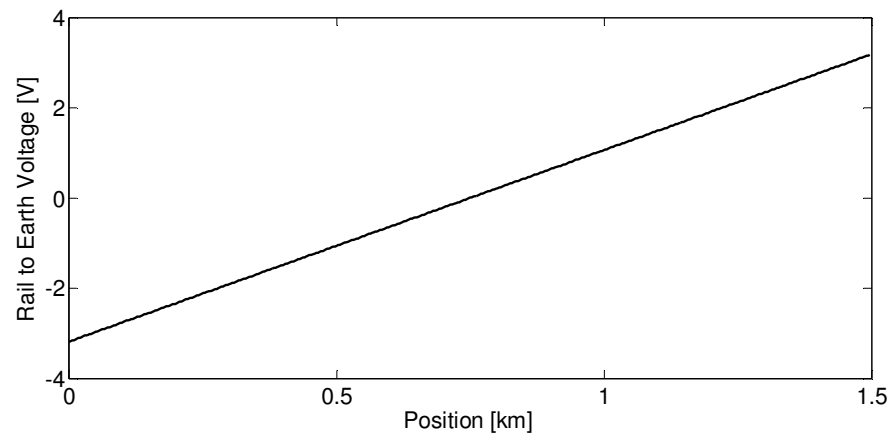

Fig. 4. Rail to earth voltage $U_{\text {re }}$ for $R_{t}=0.01 \Omega / \mathrm{km}$ and $\mathrm{G}_{\mathrm{re}}=0.8 \mathrm{~S} / \mathrm{km}$

The expression for stray current reported in the EN 50122-2 standard [2] has also been considered and found in agreement with the results shown in Fig. 3 with a maximum error of $16 \%$.

The longitudinal train position that produces the largest stray current is that in the middle; positions closer to either TPS make a larger current flow in the rails of one of the two sections, but over a shorter length, thus not leading to the maximum stray current intensity.

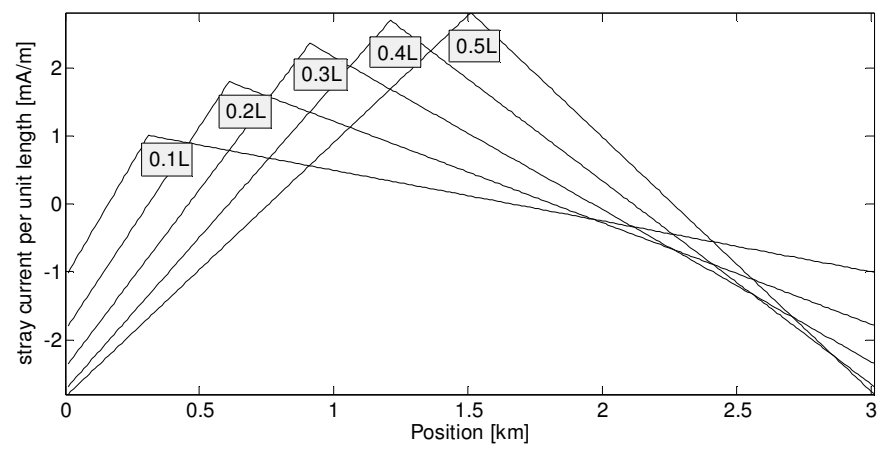

Fig. 5. Stray current as a function of train longitudinal position

\section{B. Inclusion of the stray current concrete mat}

This configuration corresponds to the one shown in Fig. 1 and considered in [10]. The resistance of the concrete mat $R_{c m}$ may be estimated by different methods, but the one proposed in [11] is followed.

$$
R_{c m}=\frac{\rho}{4 r_{c}}\left[\frac{\rho_{c}}{\rho}\left(\frac{r_{c}}{r}-1\right)+1\right]
$$

where $r_{c}$ is the external radius of the concrete and $r$ is the internal radius of the iron mass, estimated as $\sqrt{ }(\pi / \mathrm{A})$, A being the surface.

The concrete resistivity range can be very wide, depending on environment conditions of the trackbed, and normally it is assumed in the range 50-250 $\Omega \mathrm{m}$. The influence of the 
concrete resistivity is shown in Fig. 6 where the calculations are made for a soil resistivity of $100 \Omega \mathrm{m}, \mathrm{R}_{\mathrm{r}}=0.02 \Omega / \mathrm{km}$,

$\mathrm{G}_{\mathrm{r}, \mathrm{cm}}=0.5 \mathrm{~S} / \mathrm{km}$ and $1000 \mathrm{~A}$ of absorbed train current.
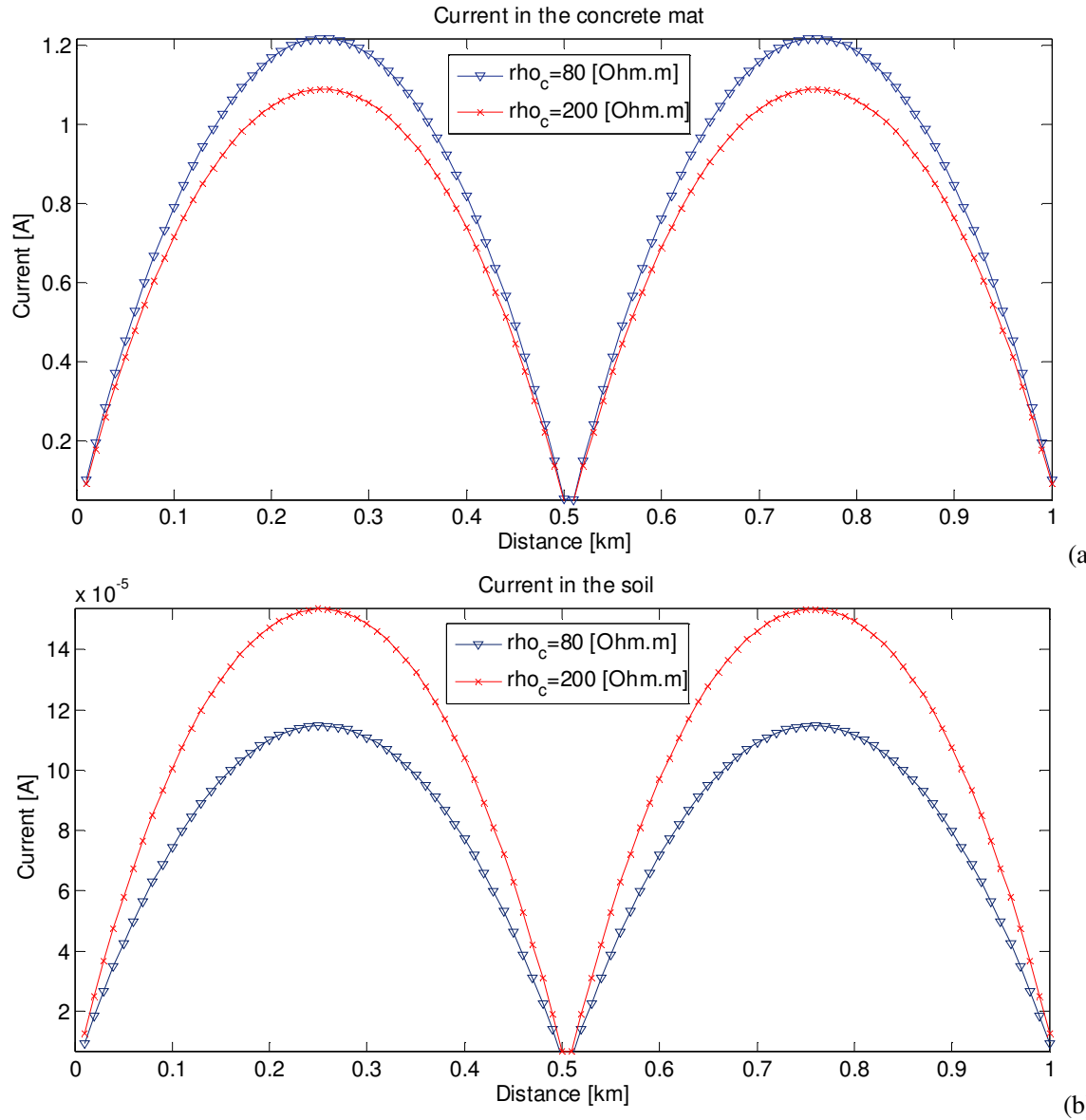

(a)

Fig. 6. Current in the (a) concrete mat and (b) soil as a function of concrete resistivity

\section{Efficiency of stray current mat and impact on buried pipe}

A buried metallic pipe is added (as shown in Fig. 7) and the efficiency of the stray current mat system is verified by simulation.

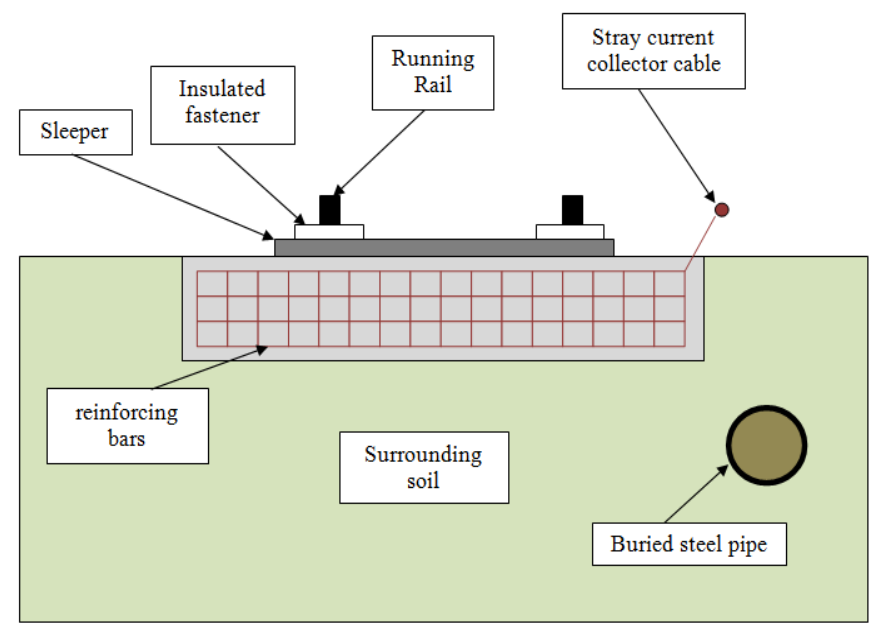

Fig. 7. Stray current mat and buried metallic pipe
Under the assumption of an ideal connection of the stray current mat to the negative terminal of the TPS by means of a diode (or a rail potential control device) that helps having cathodic protection and making the current flow unidirectional, the impact on an external buried metallic pipe is considered. The resistance to earth of the pipe has been estimated using the Dwight's expression [10][12].

For brevity the efficiency $\mathrm{E}$ of the stray current mat is introduced,

$$
E=\frac{I_{c m}}{I_{\text {leak }}} \times 100
$$

that is the ratio of the current captured by and flowing inside the stray current mat and the total leakage current leaving the rails (what was called stray current in the first example in subsection III.A).

Assuming a uniform soil model the pipe potential can be estimated with combinations of the conductance and longitudinal resistance terms that are summarized by the parameter $E$, as shown in Fig. 8 . 


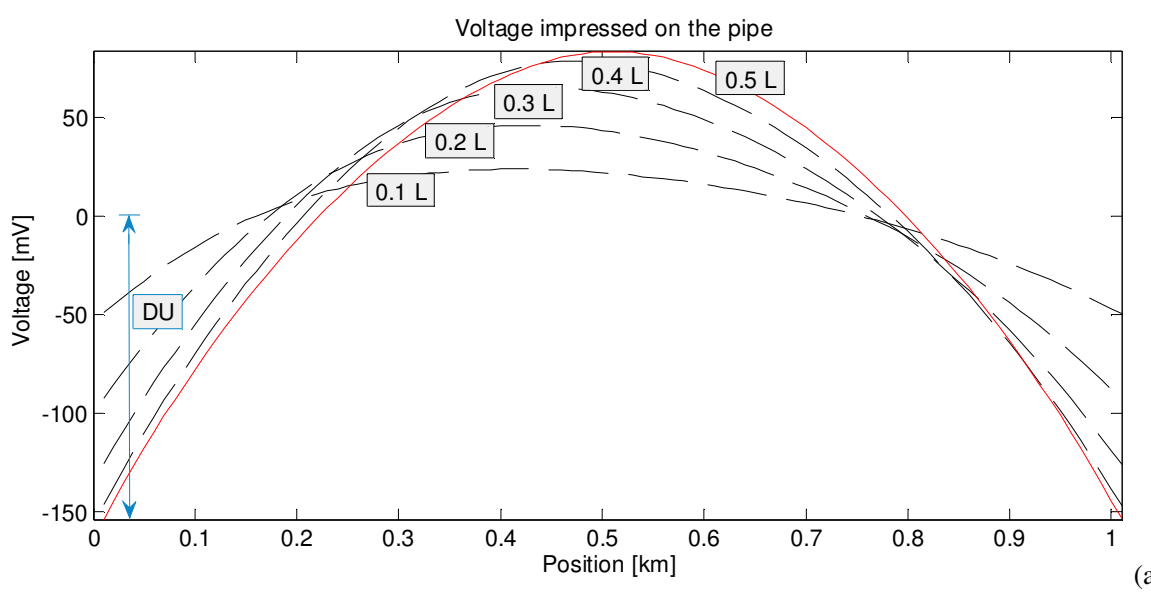

(a)

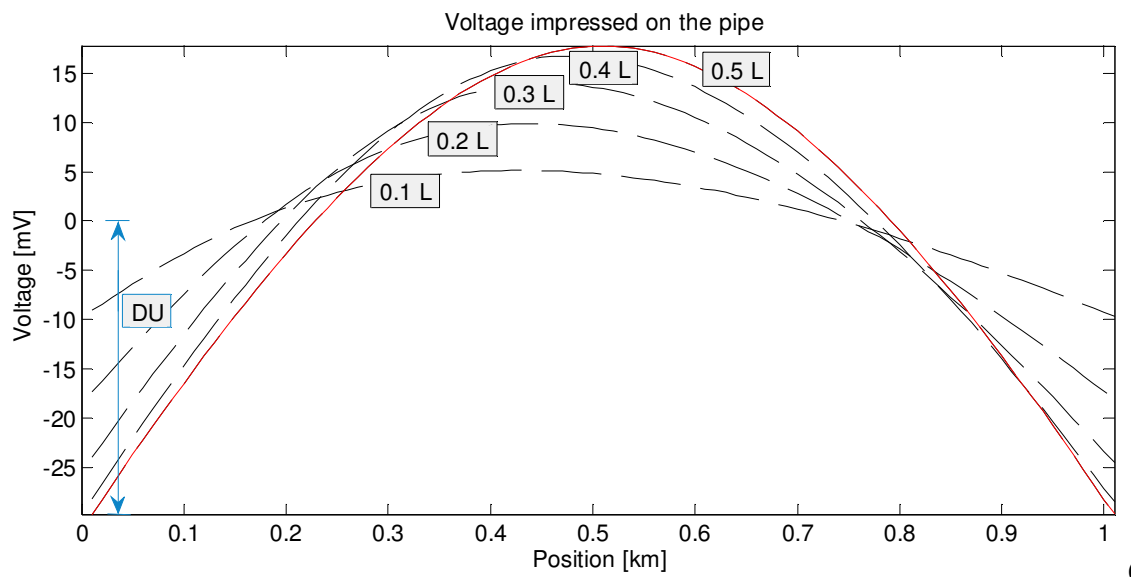

(b)

Fig. 8. Pipe potential for the uniform soil model and two stray current efficiency values: (a) 50\%, (b) $90 \%$

The uniform soil model, featuring only one layer of soil with constant resistivity and infinite depth, may lead in some cases to an overestimation of the pipe impressed potential, thus requiring unnecessary countermeasures. It was found that in particular soil resistivity configurations, where different layers can be distinguished, a multi-layer soil model is needed [13]. For a top soil layer with lower resistivity (that is the most common case) the results show a dramatic reduction of the calculated pipe potential (as shown in Fig. 9).

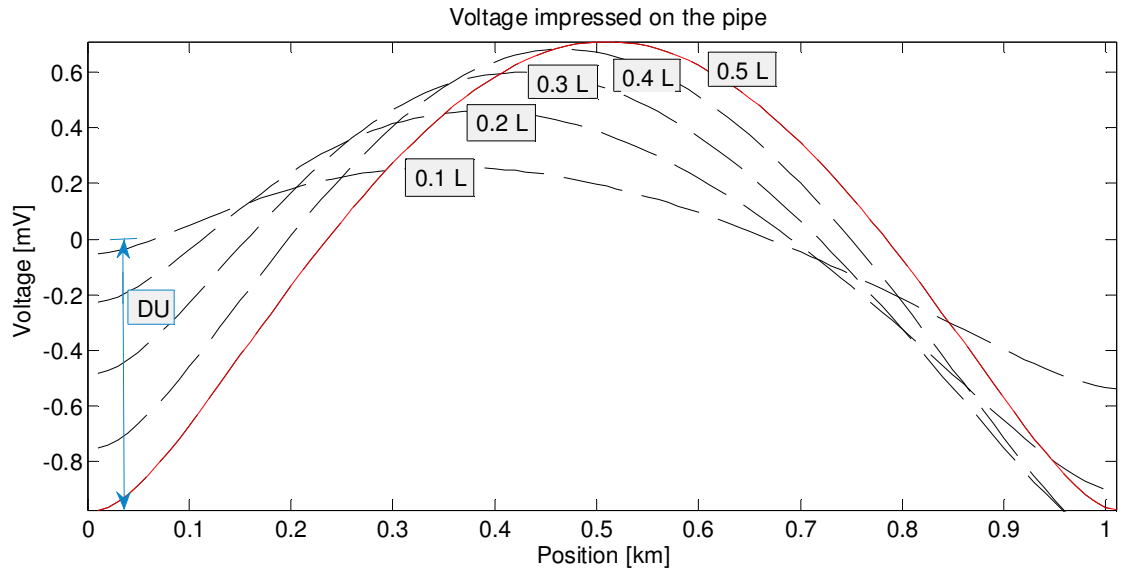

Fig. 9. Pipe potential for the two layer soil model (top layer with lowest resistivity)

If, on the contrary, the top layer has higher resistivity than the bottom one, the stray current mat efficiency decreases and the pipe potential increases (as shown in Fig. 10). 


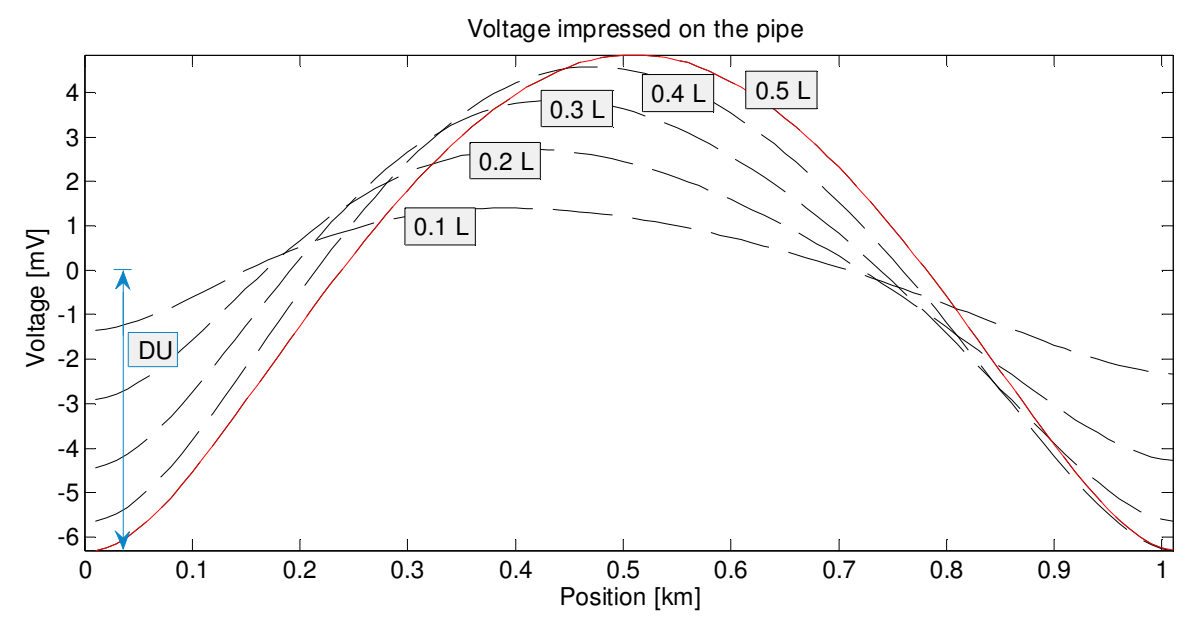

Fig. 10. Pipe potential for the two layer soil model (top layer with highest resistivity)

The two cases above (shown in Fig. 9 and 10) were using purposely extreme values of the resistivity values of the two soil layers (10 and $1000 \Omega \mathrm{m}$, exchanged in the two considered cases). A comparison between the uniform soil model and the two layer soil model for the same measured apparent resistivity values (taken from one reference case), gives the following results (see Fig. 11).

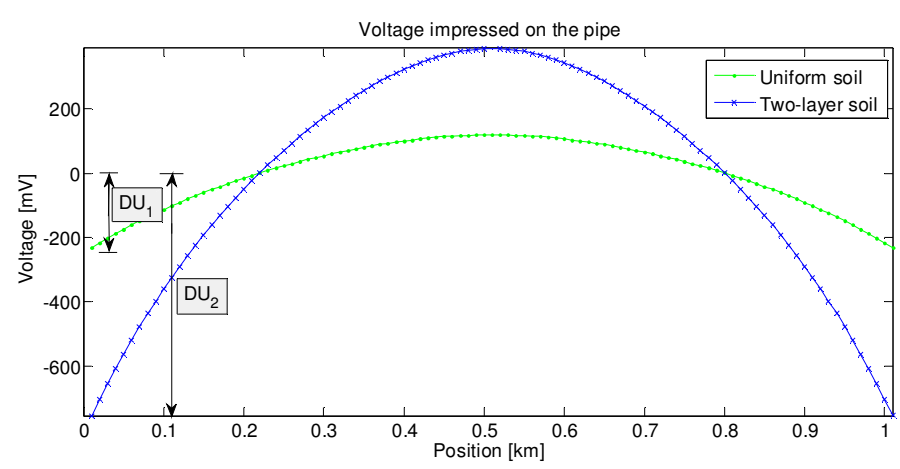

Fig. 11. Pipe potential comparing the uniform (1) and two layer soil models (2)

The difference between the values predicted by either of the two models is remarkable, has relevance for the required countermeasures and thus poses the problem of the best modeling approach when assessing the stray current phenomenon.

\section{CONCLUSION}

The problem of stray current evaluation in a DC transit system by means of simulation has been considered and solved with a lumped parameter model, compared for validation with a previous distributed parameter model [10]. This model has the possibility of including any discontinuity or simulating local defects or deviations of some parameters from the nominal or general values. Moreover, this model has been use in conjunction with both a uniform soil model and a multi-layer soil model, demonstrating the degree of approximation of the former and the reduction of the undue margins for countermeasures with the latter.

\section{REFERENCES}

[1] EN 50122 Part 2, Railway applications - Fixed installations - Part 2: Protective provisions against the effects of stray currents caused by d.c. traction systems, 1999 , pp. 1-23

[2] EN 50122 Part 2, Railway applications - Fixed installations Electrical safety, earthing and the return circuit Part 2: Provisions against the effects of stray currents caused by d.c. traction systems, 2010, pp. 1-34

[3] S. Jamali, M. Alamuti, and M. Savaghebi, "Effects of different earthing schemes on the stray current in rail transit systems," in Proc. of the UPEC 2008, 43rd Intern. Universities Power Engineering Conference, Padua, Italy, pp. 1-5, 1-4 Sept., 2008.

[4] C. Lee, "Effects of grounding schemes on rail potential and stray currents in Taipei rail transit systems," IEE Proc. Electric Power Applications, vol. 48, pp. 148-154, Mar. 2001.

[5] Chien-Hsing Lee and Chien-Jung Lu, "Assessment of grounding schemes on rail potential and stray currents in a DC transit system," IEEE Transaction on Power Delivery, vol. 21, no. 4, pp. 1941-1947, Oct. 2006.

[6] B. McCollum and K. H. Logan, Leakage of currents from electric railways., Department of Commerce, Govt. Print. Off., Washington, USA, 1916.

[7] R. D. White and E. Currens, "Earthing the London underground," in Proc. ICRE 2008, International Conference on Railway Engineering Challenges for Railway Transportation in Information Age, Hong Kong, China, pp. 1-6, 25-28 Mar. 2008.

[8] Y. S. Tzeng and C. H. Lee, "Assessment of grounding, bonding, and insulation on rail potential and stray currents in a direct current transit system," Proceedings of the Institution of Mechanical Engineers, Part F: Journal of Rail and Rapid Transit, vol. 223, no. 3, pp. 229-240, Mar. 2009.

[9] C. Charalambous and I. Cotton, "Influence of soil structures on corrosion performance of floating-DC transit systems," IET Electrical Power Applications, Vol. 1, no. 1, Jan. 2007, pp. 9-16.

[10] A. Ogunsola, A. Mariscotti and L. Sandrolini, "Estimation of Stray Current from a dc Electrified Railway and Impressed Potential on a Buried Pipe", IEEE Transactions on Power Delivery, Oct. 2012, pp. 2238-2245.

[11] B. Thapar, G. Ferrer and D.A. Blank, "Ground resistance of concrete foundations in substation yards", IEEE Trans. on Power Delivery, 1990.

[12] H. Dwight, "Calculation of resistance to ground", Electr. Eng., vol. 55, pp. 1319-1328, Dec. 1936; reprinted in Materials Performance, vol. 22, no. 4, Apr. 1983

[13] S. Jabbehdari and A. Mariscotti, "Sensitivity Analysis of Multilayer Earth Models”, ESARS 2012, Bologna, IT, Oct. 17-19, 2012. 